\title{
LINEARLY TAPERED SLOT ANTENNA WITH DIELECTRIC SUPERSTRATE
}

\author{
Rainee N. Simons* and Richard Q. Lee \\ NASA Lewis Research Center \\ MS 54-8 \\ Cleveland, Ohio 44135
}

\begin{abstract}
The effect of dielectric superstrate on a linearly tapered slot antenna (LTSA) was investigated experimentally. It was observed that the dielectric superstrate improves the directivity but generally at the expense of higher sidelobe level. The dielectric superstrate could be used to reduce the physical length and to improve the radiation characteristics of the LTSA.
\end{abstract}

\section{INTRODUCTION}

In recent years, research on linearly tapered slot antennas (LTSA) have been extensive [1], [2]. Most of these studies concerns with the performance characteristics and feeding techniques of the ITSA, and there is disproportionately little effort devoted to the study of superstrate effects on linearly tapered slot antennas. These effects are important in a stacked array antenna in which a dielectric spacer between two arrays inadvertently serves as a superstrate. The superstrate alters the guide wavelength of the LTSA and thus impacts the overall antenna design. In this paper, the effects of dielectric superstrate on the directivity and radiation patterns of a full length and reduced length LTAS will be presented and discussed.

\section{ANTENNA CONFIGURATION}

The LTSA used in the experiment is shown in Fig. 1. The LTSA having an aperture width L of $1.27 \mathrm{cms}$, a taper angle, $2 \alpha$, of $11.2^{\circ}$ and an aperture width $H$ of $1.27 \mathrm{cms}$ is etched on a $0.0508 \mathrm{~cm}$ RT/Duroid $5880 \mathrm{sub}-$ strate $\left(\epsilon_{\mathrm{r}}=2.2\right)$. The LTSA is electromagnetically coupled to a coplanar waveguide (CPW) with the center strip conductor of the CPW extented to form a CPW-toslotline transition with the LTSA. The distances $L_{s}$ from the short circuit termination of the slotline and $\mathrm{L}_{w}$ from the open termination of the extented center strip conductor to the CPW-to-slotline junction are about a quarter of a wavelength at $20 \mathrm{GHz}$. The ground

C 199.3 IEEE. Reprinted, with permission, from Proceedings of IEEE Antennas and Propagation Society International Symposium, Ann Arbor, Michigan, June 1993, pp. 1482-1485. 
plane of the CPW is connected to the antenna ground plane through via holes to ensure good impedance match and odd mode operation.

\section{RESULTS AND DISCUSSIONS}

In our experiment, the effect of superstrate was examined for LTSA with various lengths. Fig. 2 shows the measured $\mathrm{H}$ - and $\mathrm{E}$ - patterns of the regular length $(\mathrm{L}=6.6 \mathrm{~cm})$ LTSA without superstrate at $11.67,20.15$ and $22.8 \mathrm{GHz}$. Results indicate that the patterns are generally symmetrical, and the directivity increases faster in the $\mathrm{H}-\mathrm{plane}$ than in the E-plane with frequency. The measured gain of the LTSA is about $11 \mathrm{~dB}$.

The superstrate increases the electrical length as well as the effective aperture of the antenna, and thus enhances the antenna directivity. The increase in directivity is evident from the measured antenna pattern which shows a narrower main lobe. Fig. $3(a)-(b)$ displays the measured $\mathrm{H}$ - and $\mathrm{E}-\mathrm{plane}$ patterns with and without a superstrate. As indicated, the effect of the superstrate is more pronounced in the $\mathrm{H}-\mathrm{plane}$ than in the E-plane. The beamwidths of the the LTSA with and without superstrate have been recorded for frequencies ranging from 10 to $20 \mathrm{GHz}$. The results are plotted in Fig. 4. With superstrate, the beamwidth is generally narrower; however, the sidelobe level is also higher.

By reducing the length, $L$, of the LTSA, the radiation patterns become broader indicating a reduction in antenna gain. The superstrate increases the electrical length of the LTSA and enhances its directivity. The improvement in directivity results in narrower beamwidth for the LTSA with superstrate as indicated in Fig. 5. Fig. 6 shows the measured patterns of the reduced length ITSA with and without superstrate at 11 $\mathrm{GHz}$. The patterns appear symmetrical with the superstrate.

\section{CONCLUSION}

The effect of superstrate on a LTSA has been studied. Results indicate that the superstrate improves the patterns and directivity of the antenna by increasing the electrical length and effective aperture of the antenna. A superstrate can also be used to reduce the physical length of the antenna without compromising the pattern quality.

\section{REF ERENCES}

[1] K. S. Yngvesson, T. L.Korzeniowski, Y. S. Kim, E. L. Kollerg and J. F. Johansson, "The tapered 
slot antenna-a new integrated element for millimeter-wave applications", IEEE Trans. Microwave Therory Tech., Vol. 37, No. 2, Feb. 1989, pp.365374 .

[2] R. N. Simons, R. Q. Lee and T.D. Perl, "New tech nique for exciting linearly tapered slot antennas with coplanar wave guide", Electronics Letters, Vol. 28, No. 7, March 1992, pp. 620-621.

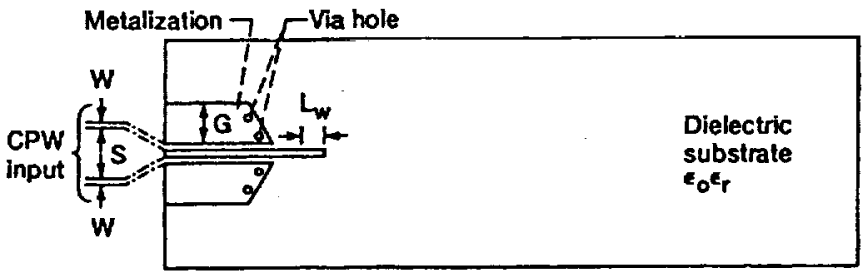

(a)

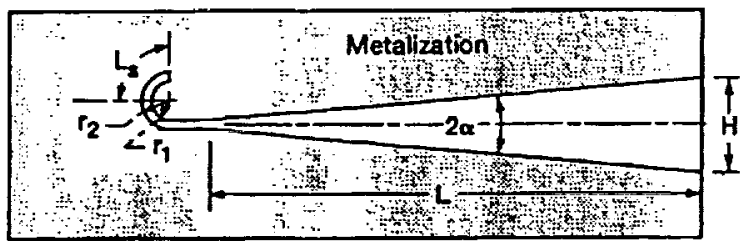

(b)

Fig. 1. Schematic for the LTSA and the CPW feed circuit $S=0.762 \mathrm{~mm}, W=0.254 \mathrm{~mm}, G=5.08 \mathrm{~mm}, L_{w}=2.951 \mathrm{~mm}$, $r_{1}=2.171 \mathrm{~mm}, r_{2}=2.425 \mathrm{~mm}, L_{s}=3.43 \mathrm{~mm}$.

(a) Top metalization is the feed structure.

(b) Bottom metallization is the antenna.

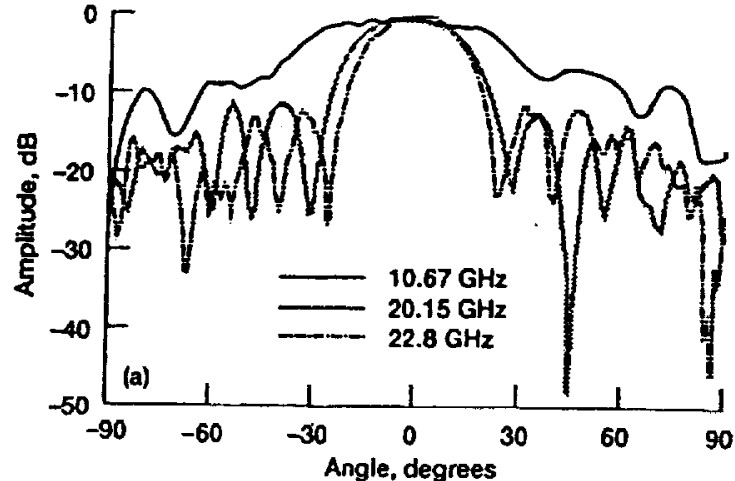

(a)

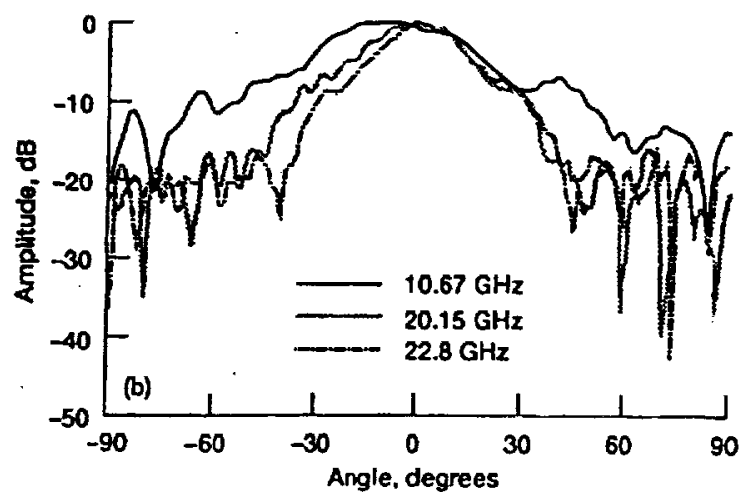

(b)

Fig. 2. Measured radiation patterns of the LTSA without a superstrate: (a) H-plane and (b) E-plane. 

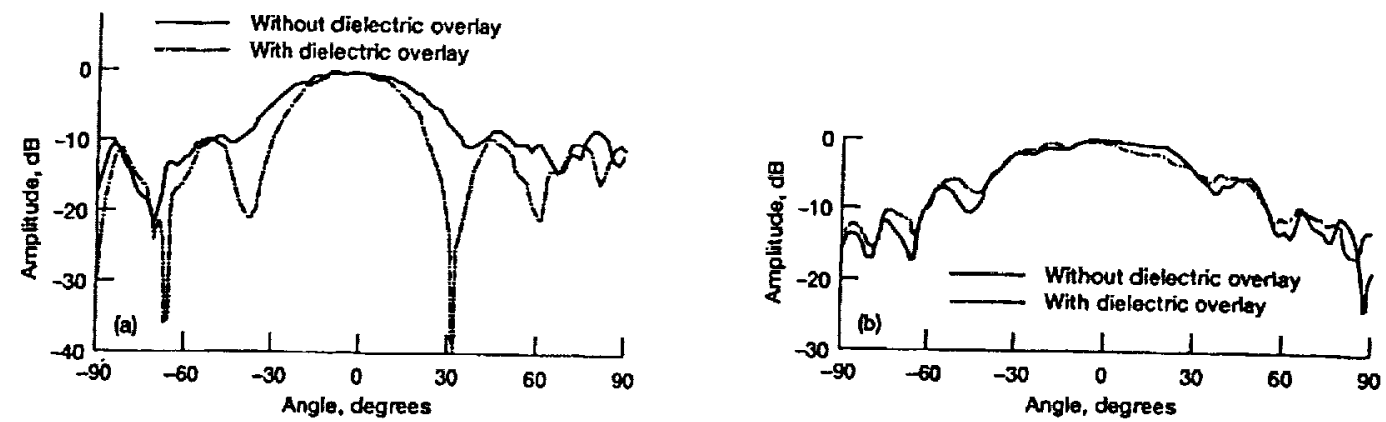

Fig. 3. Measured radiation patterns of the LTSA with and without a superstrate at $11 \mathrm{GHz}$ : (a) $\mathrm{H}-$ plane and (b) E-plane.

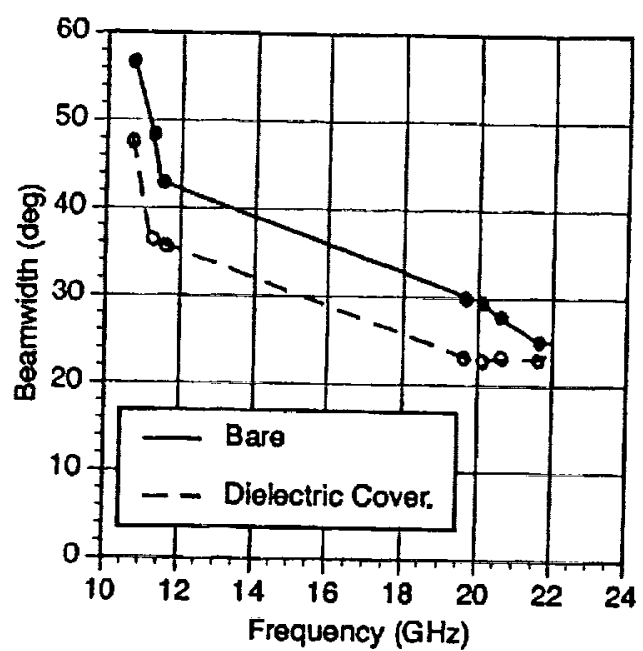

Fig. 4. Measured beamwidth vs. frequency for the LTSA with and without superstrate at $11 \mathrm{GHz}$.

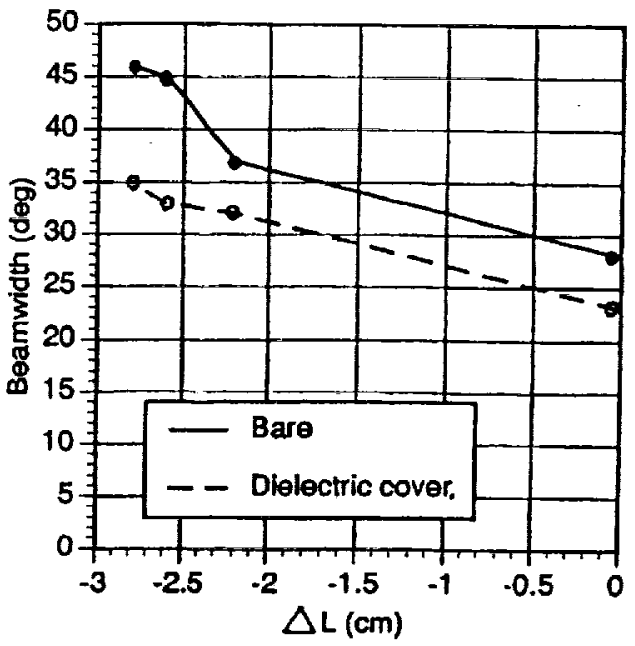

Fig. 5. Measured beamwidth vs. reduced lengths of the LTSA with and without superstrate at $11 \mathrm{GHz}$.
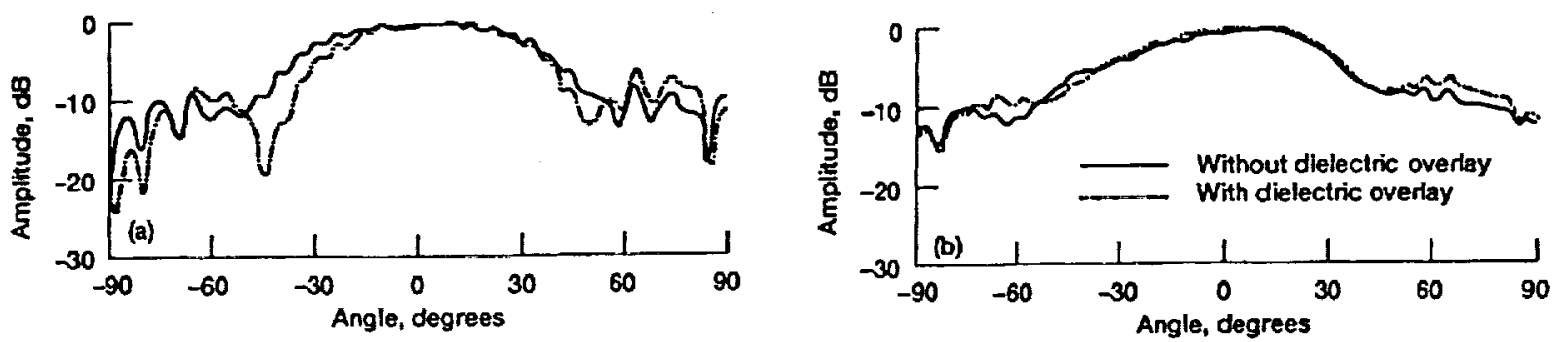

Fig. 6. Measured radiation patterns of the reduced length LTSA with and without superstrate at $11 \mathrm{GHz}$ : (a) H-plane and (b) E-plane. 


\section{EFFECT OF A DIELECTRIC OVERLAY ON A LINEARLY TAPERED SLOT ANTENNA EXCITED BY A COPLANAR WAVEGUIDE}

Rainee N. Simons, Aichard O. Lee, and Thomas D. Perl

NASA Lewis Research Center

Mail Stop 54-5

21000 Brookpark Road

Cleveland. Ohio 44135

John Silvestro

Electrical Engineering Department

Clemson University

Clemson, South Carolina

\section{KEY TERMS}

Slol antenna, coplanar waveguide, antenna feed

\section{ABSTRACT}

A lineurly nopered slor antenna (LTSA) with a dielectric overlay was experinemtally investigated. The presence of dielectric overlay alters the guite wavelengsh of the LTSA, and thus the radiation characteristics of the antenna. Results indicate that dielectric overlay could be used to reduce the physical length and to improve the radiation characieristics of the I,TSA. O I993 John Wiley \& Sons. Inc.

\section{INTRODUCTION}

The linearly tapered slot antenna (LTSA) has been developed for potential millimeter-wave applications, e.g., as a radiating element for reflector or lens antennas. Compared to other types of printed circuit antennas, these end-fire antennas have higher directivity, broader bandwidth, and less spatial constraint for solid-state device integration [1]. The LTSA has been studied extensively in the past decade. Most of these studies concern the performance characteristics and feeding techniques of the LTSA [2, 3]. Recently, a LTSA of nonplanar geometry fed with a balanced microstrip line has also been reported to have excellent radiation and bandwidth characteristics [4]. Despite all these efforts, little information is available on the effects of dielectric overlays on linearly tapered slot antennas. These effects are important in a stacked array antenna in which a dielectric spacer between two arrays inadvertently serves as an overlay. In addition, the dielectric overlay changes the guide wavelength of the LTSA and thus impacts the overall antenna design. In this article we report our experimental findings of the effects of dielectric overlay and also the effects of reduction in physical length of the LTSA on the radiation patterns.

\section{DESIGN AND FABRICATION}

Figure 1 shows the layout of the LTSA which has a physical length $L$ of $6.6 \mathrm{~cm}$, a taper angle, $2 \alpha$, of 11.2 degrees, and an aperture width $H$ of $1.27 \mathrm{~cm}$. The LTSA is electromagnerically coupled to a coplanar waveguide (CPW) feed etched on the opposite side of a $0.0508-\mathrm{cm}$ RT/Duroid 5880 substrate $\left(\epsilon_{r}=2.2\right)$. The finite ground plane of the CPW is connected to the antenna ground plane via holes to ensure good impedance match and odd-mode operation. For efficient power coupling, the center strip conductor of the CPW is extended to form a CPW-to-slot-line transition with the LTSA. The distance $L_{s}$ from the short-circuit termination of the slot line, the $L_{w}$ from open termination of the extended center strip conductor, to the CPW-to-slot-line junction are about a quarter of a wavelength at the center frequency of $20 \mathrm{GHz}$. To provide a smooth transition, the slot line at the feed end has a circular bend instead of a right-angle bend.

\section{RESULTS AND DISCUSSIONS}

In our experiments, the effect of dielectric overlay was examined for LTSA with regular and reduced lengths. These results were compared to those of identical LTSA without dielectric overlay. The experimental findings are summarized below.

A. Regular-Length LTSA Performance. The measured return loss is displayed in Figure 2, which shows a 2:1 VSWR bandwidth of $20 \mathrm{GHz}$ over a frequency range of $10-30 \mathrm{GHz}$. These results indicate that the regular-length $(L=6.6 \mathrm{~cm})$ LTSA without overlay has ultrawideband characteristics and good impedance match. Typical measured $H$ - and $E$-plane radiation patterns are shown in Figures $3(\mathrm{a})$ and $3(\mathrm{~b})$, respectively. The patterns are generally symmetrical over a wide range of frequencies. Results also indicate that the directivity increases faster in the $H$ plane than in the $E$ plane with increasing frequency. The measured gain of the LTSA is about $11 \mathrm{~dB}$.

B. Overlay Effecr. The effect of the overlay was found to have a significant effect on the regular-length LTSA at the lower end of the frequency band. At these frequencies, the

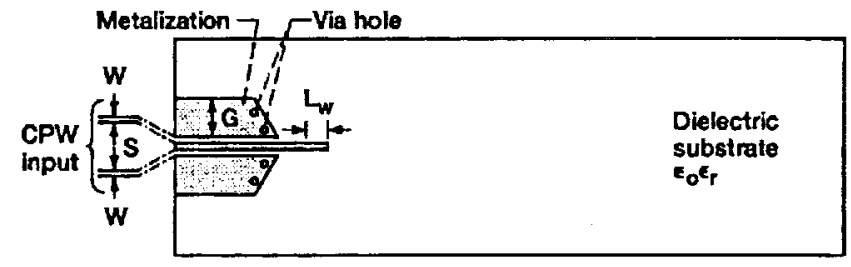

(a)

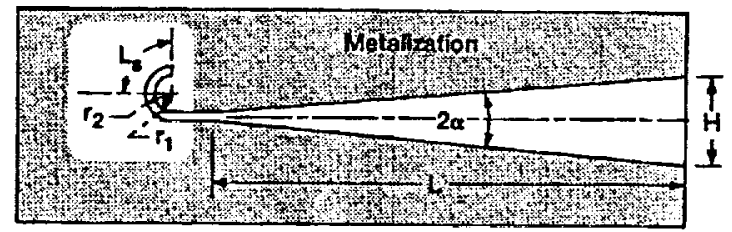

(b)

Figure 1 Schemalic for the LTSA and the CPW feed circuit. (a) Top metallization is the feed structure. (b) Bottom mctallization is the antenna. $S=0.762 \mathrm{~mm}, W=0.254 \mathrm{~mm}, G=5.08 \mathrm{~mm}, L_{\mathrm{a}}=2.951 \mathrm{~mm} . r_{1}=2.171 \mathrm{~mm}, r_{2}=2.425 \mathrm{~mm}, L_{\mathrm{s}}=3.43 \mathrm{~mm}$

(c) Microwave and Optical Technology Letters/vol. 6, no. 4, 1993. Reptinted by permission of John Wiley \& Sons, Inc. 


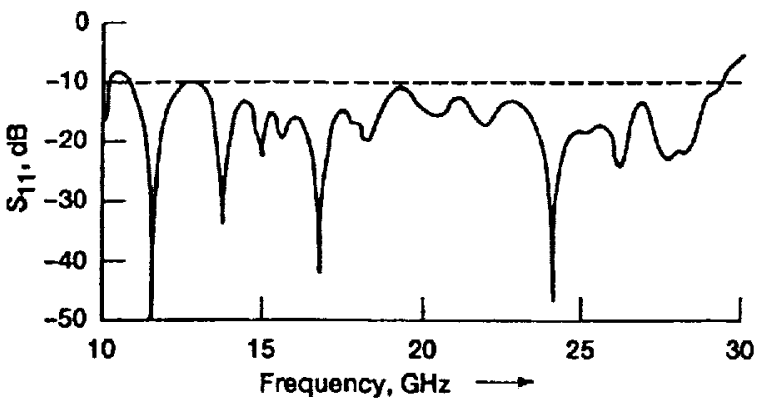

Figure 2 Measured return loss $\left(S_{11}\right)$ as a function of frequency.
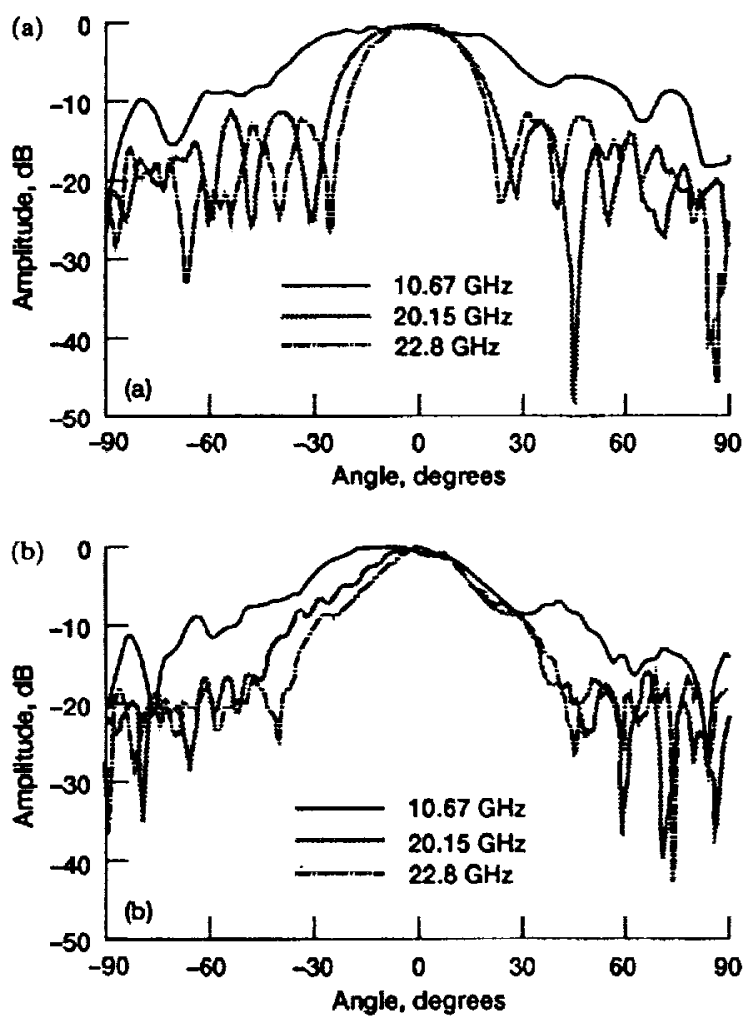

Figure 3 Measured radiation patterns of the regular-length LTSA without a dielectric overlay at $10.67,20.15$. and $22.8 \mathrm{GHz}$. (a) $H$ plane. (b) $E$ plane

electrical length and the effective aperture are small; hence the directivity is low and the beamwidth is broad. By introducing an overlay. the electrical length as well as the effective aperture are increased, thus enhancing the directivity. The increase in directivity is evident from the measured antenna pattern which now has a narrower main lobe. Figures $4(a)$ and $4(b)$ illustrate the measured $H$ - and $E$-plane radiation patterns without and with an overlay. These patterns further indicate that the effect of overlay is more pronounced in the $H$ plane than in the $E$ plane. This is due to the fact that in the $E$ plane, the incident wave is perpendicular to the plane of the substrate.

C. Reduced-Lengsh LTSA Performance. By reducing the length $L$ from 6.6 to $4.4 \mathrm{~cm}$ the radiation pattern broadens due to reduction in gain. By providing a dielectric overlay the
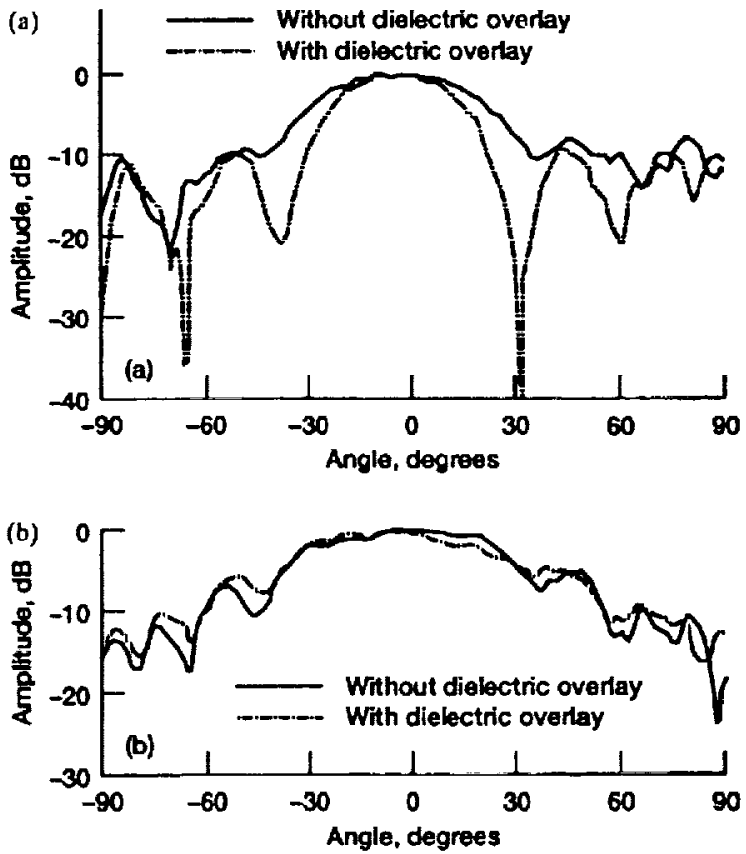

Figure 4 Measured radiation patterns of the regular-length LTSA without and with a dielectric overlay at $11 \mathrm{GHz}$. (a) $H$ pline. (b) $E$ plane
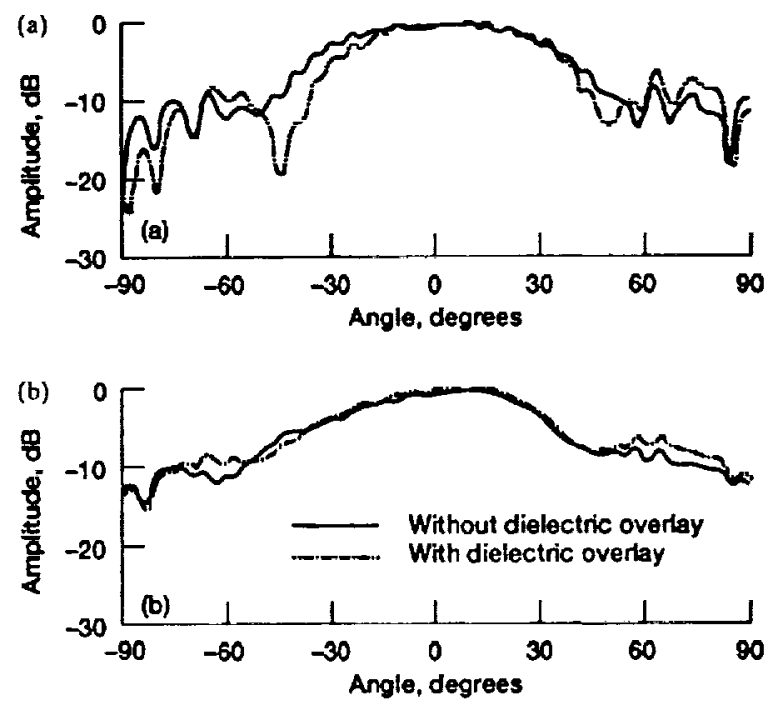

Figure 5 Measured radiation patterns of the reduced-length LTSA without and with a dielectric overlay at $11 \mathrm{GHz}$. (a) $H$ plane. (b) $E$ plane

electrical length of the LTSA increases and the directivity improves. The improvement in directivity is evident from the patterns shown in Figures 5(a) and 5(b).

\section{CONCLUSION}

The effect of dielectric overlay on a LTSA has been studied. The LTSA under study exhibits vcry wide bandwidth and excellent radiation patterns. A dielectric overlay improved the patterns and directivity of the antenna by increasing the electrical length and effective aperture of the antenna. A 


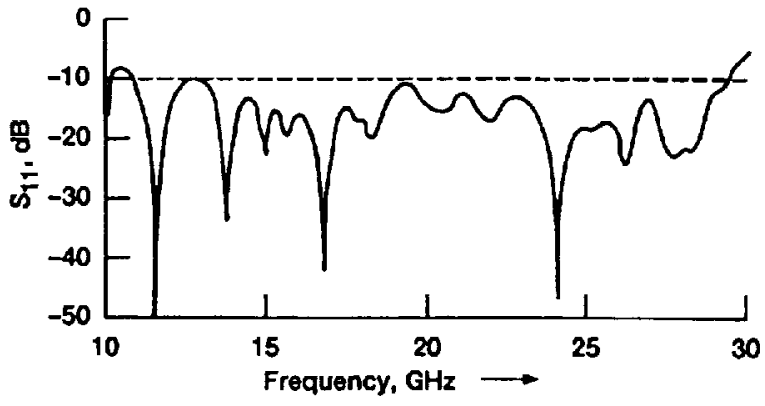

Figure 2 Measured return loss $\left(S_{11}\right)$ as a function of frequency.
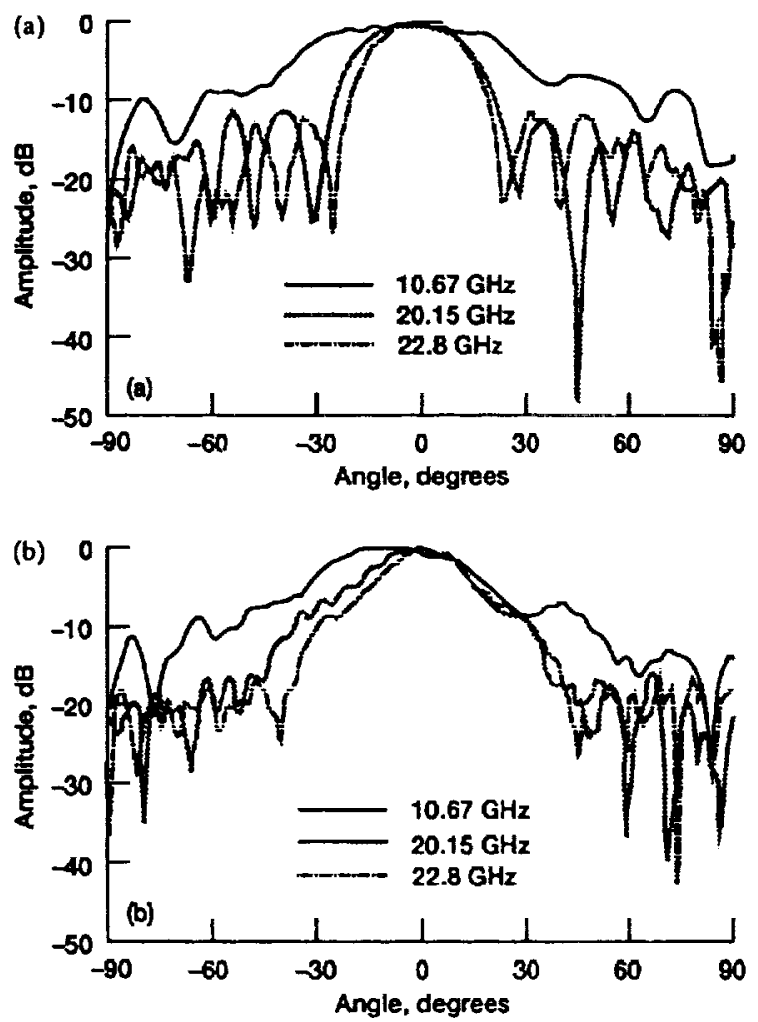

Figure 3 Measured radiation pattcrns of the regular-length LTSA without a dielectric overlay at $10.67,20.15$. and $22.8 \mathrm{GHz}$. (a) $H$ plane. (b) E plane

electrical length and the effective aperture are small; hence the directivity is low and the beamwidth is broad. By introducing an overlay. the electrical length as well as the effective aperture are increased, thus enhancing the directivity. The increase in directivity is evident from the measured antenna pattern which now has a narrower main lobe. Figures 4(a) and $4(b)$ illustrate the measured $H$-and $E$-plane radiation patterns without and with an overlay. These patterns further indicate that the effect of overlay is more pronounced in the $H$ plane than in the $E$ plane. This is due to the fact that in the $E$ plane, the incident wave is perpendicular to the plane of the substrate.

C. Reduced-Length LTSA Performance. By reducing the length $L$ from 6.6 to $4.4 \mathrm{~cm}$ the radiation pattern broadens due to reduction in gain. By providing a dielectric overlay the
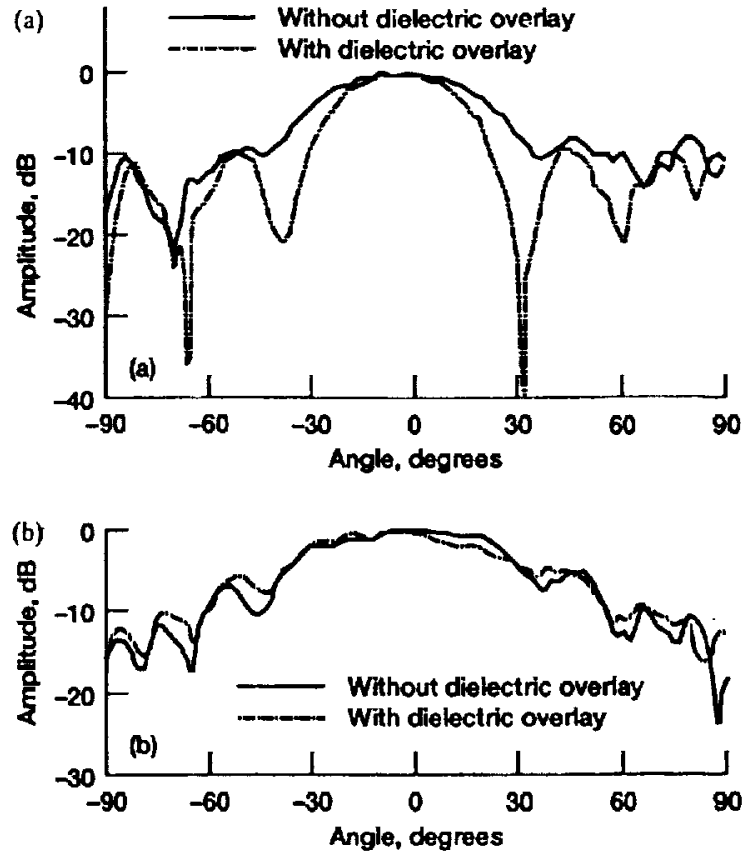

Figure 4 Measured radiation patterns of the regular-length LTSA without and with a dielectric overlay at $11 \mathrm{GHz}$. (a) $H$ plane. (b) $E$ plane
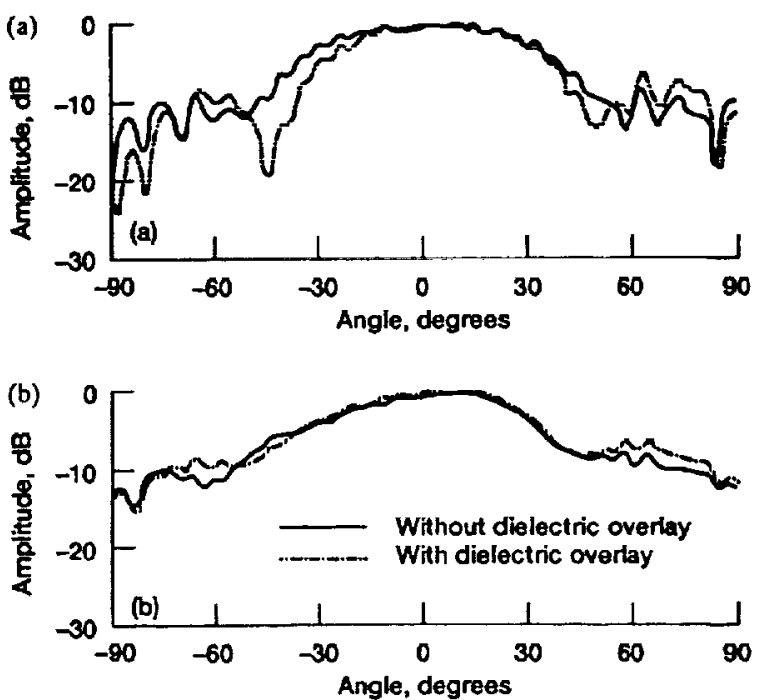

Figure 5 Measured radiation patterns of the reduced-length LTSA without and with a dielectric overlay at $11 \mathrm{GHz}$. (a) $H$ plane. (b) $E$ plane

electrical length of the LTSA increases and the directivity improves. The improvement in directivity is evident from the patterns shown in Figures $5(\mathrm{a})$ and $5(\mathrm{~b})$.

\section{CONCLUSION}

The effect of dielectric overlay on a LTSA has been studied The LTSA under study exhibits very wide banduidth and excellent radiation patterns. A dielectric overlay improved the patterns and directivity of the antenna by increasing the electrical length and effective aperture of the antenna. A 
dielectric overlay can also be used to reduce the physical length of the antenna without compromising the pattern quality.

\section{REFERENCES}

1. K. S. Yingvesson. T. L. Korzeniowski, Y. S. Kim. E. L. Kollberg. and J. F. Johansson. "The Tapered Slot Antenna-A New Integrated Element for Millimeter-Wave Applications," IEEE Trans. Microwave Theory Tech., Vol. MTT-37, No. 2, Feb. 1989, pp. $365-574$.

2. A. Nesic. "Endfirc Slotline Antennas Excited by a Coplanar Waseguide." IEEE Antennas and Propagation Society Internarionul Symposium Digest, 1991, pp. 700-71)2.

3. R. V. Simons. R. O. Lee, and T. D. Perl. "New Technique for Exciting Linearly Tapered Slor Antennas with Coplanar Waveguide." Electron. Lell., Vol. 28. No. 7. March 1992, pp. 620-621.

4. R. N. Simons, R. Q. Lee. and T. D. Perl. "Non-Planar Linearly Tapered Slot Antenna with Balanced Microstrip Feed." 1992 IEEE .tutennas and Propagation International Symposium Digest. Vol. 4. pp. $2109-2112$.

Received $9-25-92$ 


\title{
CHARACTERISTICS OF LINEARLY TAPERED SLOT ANTENNA WITH CPW FEED
}

\section{ON HIGH RESISTIVITY SILICON}

\author{
Rainee N. Simons \\ Sverdrup Technology, Inc. \\ Lewis Research Center Group \\ Brook Park, Ohio 44142 \\ -and \\ Susan R. Taub and Richard Q. Lee \\ National Aeronautics and Space Administration \\ Lewis Research Center \\ Cleveland, Ohio 44135
}

\section{SUMMARY}

A linearly tapered slot antenna (LTSA) has been fabricated on a high resistivity silicon substrate and tested at C-Band frequencies. The LTSA is electromagnetically coupled to a coplanar waveguide (CPW) feed. In this paper, the measured radiation patterns, gain and return loss are presented and discussed.

\section{INTRODUCTION}

Linearly tapered slot antennas (LTSA's) have many exceptional features such as narrow beamwidth, high element gain, wide bandwidth and small transverse spacing between elements in an array. These features make them attractive in satellite communication antennas (ref. 1). Previously reported LTSA antennas are fabricated on low dielectric constant RT-5880 Duroid substrate (refs. 2 to 4). This paper describes the design and performance of a LTSA constructed on a high resistivity silicon substrate. By choosing a silicon substrate with sufficiently high resistivity it is possible to make the dielectric attenuation constant of the microwave transmission line for the feed network approach that of GaAs (ref. 5). Compared to designs presented earlier, the new design has smaller dimensions because of the higher dielectric constant of silicon. In addition, the use of silicon provides for the potential of integration with silicon MMIC's and digital control circuits. Lastly, when compared with $\mathrm{GaAs}$, silicon wafers are available in much larger diameters and at lower cost thus facilitating integration of active devices, antenna and control circuits on a single wafer.

\section{ANTENNA DESIGN AND FABRICATION}

The antenna and the feed network are fabricated on a single 5000 to $10,000 \Omega$-cm silicon wafer. The thickness of the wafer is $0.381 \mathrm{~mm}$ with $\varepsilon_{\mathrm{r}}=11.7$. The thickness of the gold metalization is about $2.5 \mu \mathrm{m}$ which is about three times the skin depth at the center frequency $\mathrm{f}_{\mathrm{o}}$ of $6 \mathrm{GHz}$. This substrate has an effective thickness ratio (ref. 1) of 0.02 which is within the optimum range for high gain and low side lobes. Figure 1 shows a feed with electromagnetic coupling between a grounded CPW (GCPW) and slotline which are on opposite sides of a silicon wafer (ref. 6). At the GCPW input port, $Z_{0}$ is $50 \Omega$ while close to the transition to the slotline $Z_{0}$ is $60 \Omega$. The $Z_{0}$ of the slotline is $70 \Omega$. The distances $L_{s}$ and $L_{m}$ are $\sim \lambda_{g(s l o t l i n e)} / 4$ and $\lambda_{g(\text { microstrip) }} / 4$, respectively at $f_{0}$. The LTSA is formed by gradually flaring the width of the slotline by an angle $2 \alpha$. When $2 \alpha$ is close to 11 degrees a symmetric beam width is achieved for an antenna on Duroid (ref. 1). A symmetric beam results in high aperture efficiency if used for illuminating a reflector. The width $H$ of the antenna is 


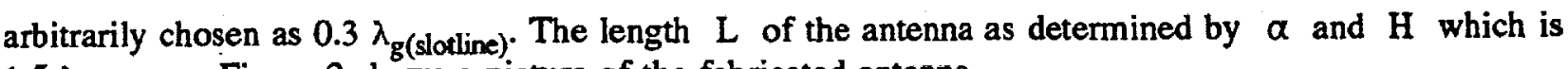
$1.5 \lambda_{\mathrm{g} \text { (slotline) }}$. Figure 2 shows a picture of the fabricated antenna.

\section{ANTENNA PERFORMANCE AND DISCUSSIONS}

The measured return loss $\left(S_{11}\right)$ at the coaxial input port of the feed network is shown in figure 3 . The return loss is observed to be better than $-10 \mathrm{~dB}$ (2:1 VSWR) over a frequency range extending from 6 to $8 \mathrm{GHz}$. Although, the antenna has been designed at $6 \mathrm{GHz}$, the best return loss oceurs at about $7 \mathrm{GHz}$. This could be due to double side processing of the wafer which might have inadvertently offset the feed resulting in a shorter stub length. Typical measured $\mathrm{E}$ - and $\mathrm{H}$-plane radiation pattems are shown in figure 4 . The patterns are found to have good characteristics. The measured gain of the antenna is 5,7 , and $9 \mathrm{~dB}$ at 5,7 , and $9.4 \mathrm{GHz}$, respectively. Lastly, optimization of the LTSA on silicon has not been carried out and better performance might be expected with improvements.

\section{CONCLUSIONS}

The design and performance characteristics of a LTSA fabricated on high resistivity silicon wafer is presented. The LTSA exhibits good impedance match and radiation patterns.

\section{ACKNOWLEDGMENT}

The authors would like to thank Paul G. Young for the fabrication of the antenna.

\section{REFERENCES}

1. Yngvesson, K.S., et al.: The Tapered Slot Antenna - A New Integrated Element for Millimeter-Wave Applications. IEEE Trans. Microwave Theory Tech., vol. MTT-37, no. 2, Feb. 1989, pp. 365-374.

2. Yngvesson, K.S., et al.: Endfire Tapered Slot Antennas on Dielectric Substrates. IEEE Trans. Antennas Propagat., vol. AP-33, no. 12, Dec. 1985, pp. 1392-1399.

3. Nesic, A.: Endfire Slot Line Antennas Excited by a Coplanar Waveguide. IEEE Antennas and Propagation Society International Symposium Digest, vol. 2, IEEE, Piscataway, NJ, 1991, pp. 700-702.

4. Simons, R.N., et al.: New Techniques for Exciting Linearly Tapered Slot Antennas with Coplanar Waveguide. Electron. Lett., vol. 28, no. 7, Mar. 1992, pp. 620-621.

5. Rosen, A., et al.: Silicon as a Millimeter-Wave Monolithically Integrated Substrate - A New Look. RCA Rev., vol. 42, Dec. 1981, pp. 633-660.

6. Simons, R.N., ê al.: Novel Coplanar Waveguide to Slotline Transition on High Resistivity Silicon. Electron. Lett., vol. 28, no. 24, Nov. 1992, pp. 2209-2210. 


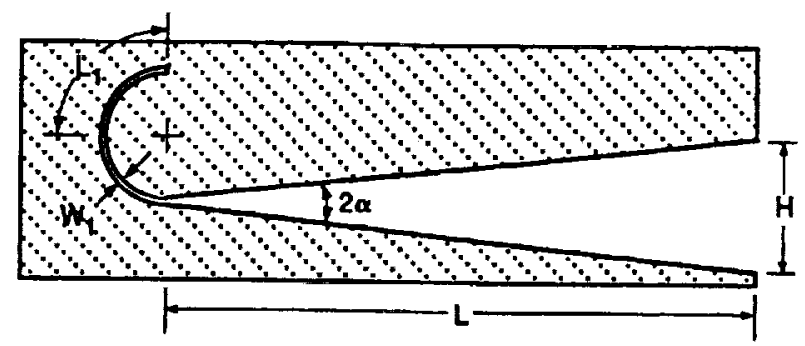

(a) Front side metalization.

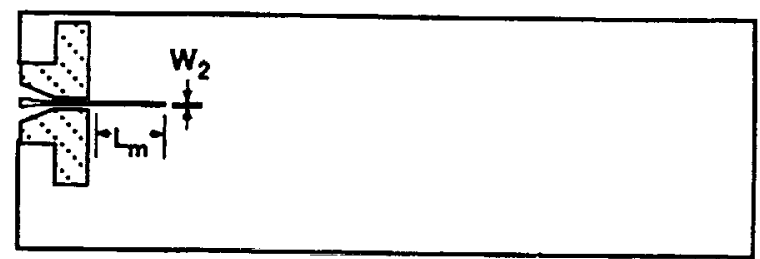

(b) Back side metalization.

Figure 1. Schematic of the linearly tapered slot antenna. $W_{s}=0.16 \mathrm{~mm}, W_{m}=0.15 \mathrm{~mm}$.

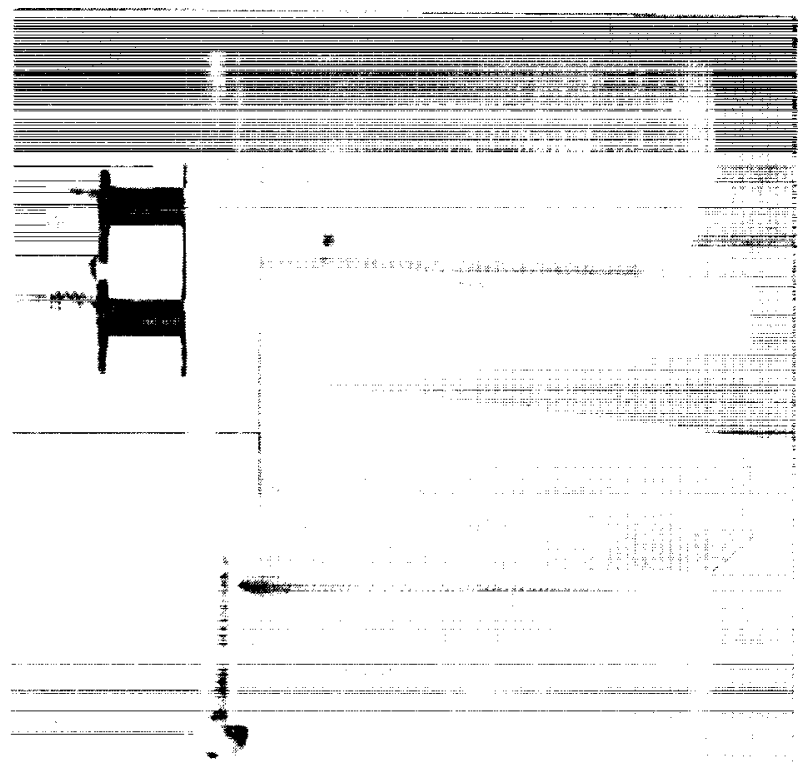

C- $92-10623$

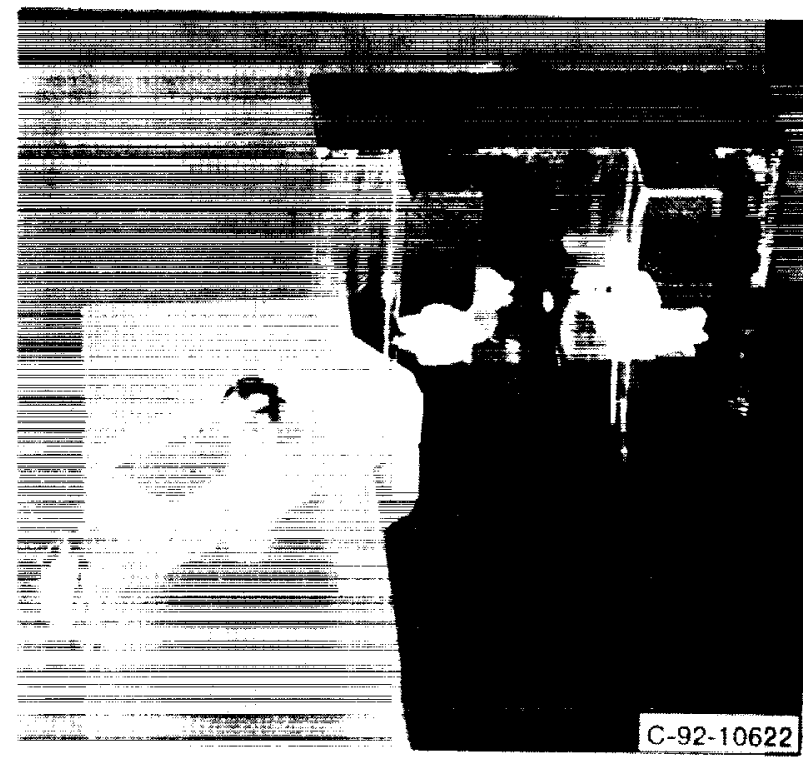

(b) Coplanar Waveguide Feed (CPW) for Linearty Tapered Slot Antenna on silicon.

Figure 2.-Photograph of the antenna. 


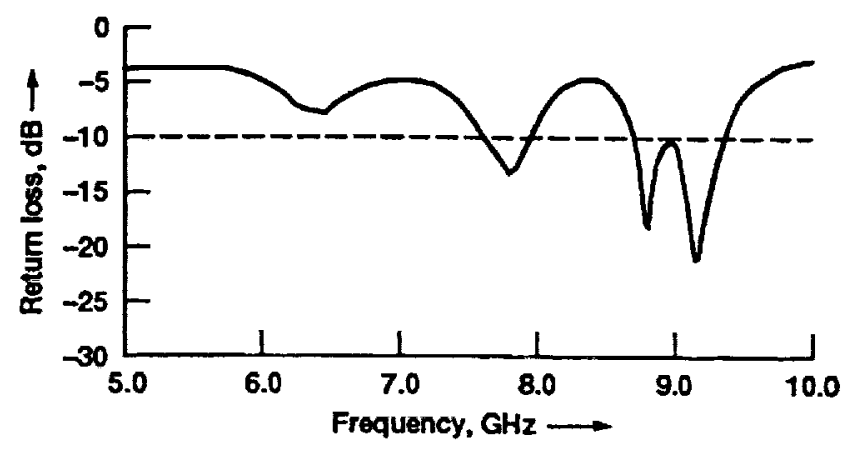

Flgure 3.- Measured retum loss $\left(S_{11}\right)$ at the coaxial input port.

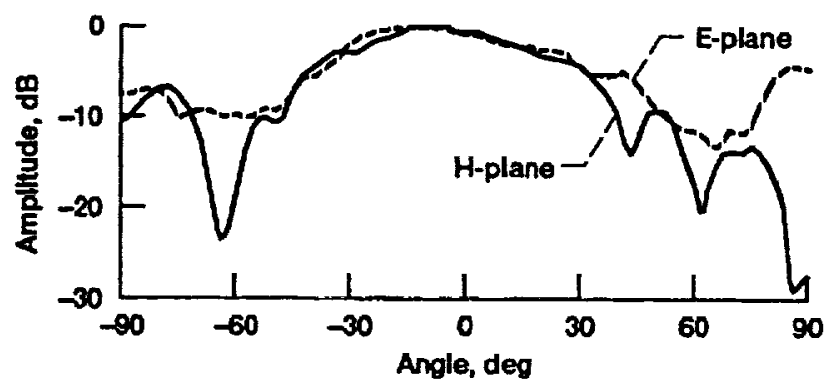

Figure 4.-Measured radlation pattern of the LTSA at $7 \mathrm{GHz}$. 
NONPLANAR LINEARLY TAPERED SLOT ANTENNA WITH BALANCED

MICROSTRIP FEED

\author{
Rainee N. Simons \\ Sverdrup Technology, Inc. \\ Lewis Research Center Group \\ Brook Park, Ohio 44142 \\ Richard Q. Lee \\ National Aeronautics and Space Administration \\ Lewis Research Center \\ Cleveland, Ohio 44135 \\ and \\ Thomas D. Perl \\ University of Akron \\ Akron, Ohio 44325
}

\begin{abstract}
A nonplanar linearly tapered slot antenna (LTSA) has been fabricated and tested at frequencies from 8 to $32 \mathrm{GHz}$. The LTSA is excited by a broadband balanced microstrip transformer. The measured results include the input return loss as well as the radiation pattern of the antenna.
\end{abstract}

\title{
INTRODUCTION
}

Linearly tapered slot antennas (LTSAs) have many salient features such as narrow beam width, high element gain, wide bandwidth and small transverse spacing between elements in an array. These features make them attractive in satellite communication antennas involving beam shaping and switching (ref. 1). Previously reported LTSA antennas are excited either by a fin line (ref. 2), coplanar waveguide (CPW) (ref. 3), or by a microstrip to slot line transition (ref. 3). The latter makes use of quarter wavelength stubs for impedance matching and hence the 2:1 VSWR bandwidth of the circuit is very small (ref. 3 ).

This paper describes the design and performance of a LTSA excited by a balanced microstrip (fig. 1). Compared to the fin line feed, the new design is smaller, less complex, and is not limited to a waveguide band. In addition, when compared to CPW or microstrip/slot line feed, the new design eliminates the necessity of quarter wavelength stubs and hence has a much wider bandwidth. 


\section{BALANCED MICROSTRIP FEED DESIGN}

The feed system, as shown in figure 1 , consists of a conventional microstrip on a dielectric substrate of thickness $D$ with the ground plane tapered to a width equal to the strip width $W(0.071 \mathrm{~cm})$ to form a balanced microstrip. The radius $R_{2}$ of the arc is arbitrarily chosen as half free space wavelength $\left(\lambda_{o} / 2\right)$ at the design frequency $\left(f_{o}\right)$ of $18 \mathrm{GHz}$. The taper helps to match the characteristic impedance of the conventional microstrip (50 $\Omega$ ) to the balanced microstrip. The characteristic impedance of the balanced microstrip is chosen as $\approx 160 \Omega$ which is equal to the input impedance of the LTSA. This input impedance is twice the input impedance of a regular half LTSA above a ground plane $(\approx 80 \Omega)$ (ref. 2). The electric field lines at various cross sections along the feed and the antenna are shown in figure 2 . The electric field lines which are spread out in the conventional microstrip concentrate between the metal strips of the balanced microstrip and finally rotate while travelling along the axis of the antenna.

\section{NONPLANAR LTSA DESIGN}

The nonplanar LTSA is formed by gradually flaring the strip conductors of the balanced microstrip on opposite sides of the dielectric substrate by an angle $\alpha$ with respect to the antenna axis. A symmetric beam width is necessary while illuminating a reflector for maximum aperture efficiency; this is achieved is $2 \alpha$ is close to $11^{\circ}$ (ref. 1). Hence $\alpha$ is chosen as $5.3^{\circ}$ in our design. The radius $R_{1}$ of the arc is arbitrarily chosen as $0.9 \lambda_{0}$. In order for the LTSA to operate as a travelling wave antenna, the width $H$ must be greater than $\lambda_{o} / 2$ (ref. 1); hence, $H$ is chosen as $0.75 \lambda_{0}$. The length $L$ of the antenna as determined by $\alpha$ and $H$ is $4.3 \lambda_{0}$. The entire circuit is fabricated on $0.0508 \mathrm{~cm}$ thick RT/Duroid $5880\left(\varepsilon_{\mathrm{r}}=2.2\right)$ substrate. This substrate has an effective thickness ratio of 0.03 which is within the optimum range for high gain and low side lobes (ref. 1).

\section{ANTENNA PERFORMANCE AND DISCUSSIONS}

The measured return loss $\left(\mathrm{S}_{11}\right)$ at the coaxial input port of the feed network is shown in figure 3. The return loss is observed to be better than $-10 \mathrm{~dB}(2: 1 \mathrm{VSWR})$ over a frequency range extending from 8 to $32 \mathrm{GHz}$. This is a significant improvement over the LTSA reported in the literature (ref. 3 ).

The measured E- and H-plane radiation patterns at three different frequencies are shown in figures $4(\mathrm{a})$ and (b) respectively. The measured patterns are found to be excellent.

The measured H-Plane cross-polarized radiation is $-16 \mathrm{~dB}$ below the copolarized radiation at $f_{o}$. Further improvement could be achieved by varying the substrate thickness.

\section{CONCLUSIONS}

The design and performance characteristics of a LTSA with a balanced microstrip feed network has been presented. A LTSA fed with this feed network exhibits very broad bandwidth extending from X-band to Ka-band with good impedance match and excellent radiation patterns. 


\section{REFERENCES}

1. Yngvesson, K.S., et al.: The Tapered Slot Antenna - A New Integrated Element for Millimeter-Wave Applications. IEEE Trans. Microwave Theory Tech., vol. MTT-37, no. 2, Feb. 1989, pp. 365-374.

2. Yngvesson, K.S., et al.: Endfire Tapered Slot Antennas on Dielectric Substrates. IEEE Trans. Antennas Propag., vol. AP-33, no. 12, Dec. 1985, pp. 1392-1399.

3. Nesic, A.: Endfire Slot Line Antennas Excited by a Coplanar Waveguide. IEEE AP-S International Symposium Digest, IEEE, New York, 1991, pp. 700-702.

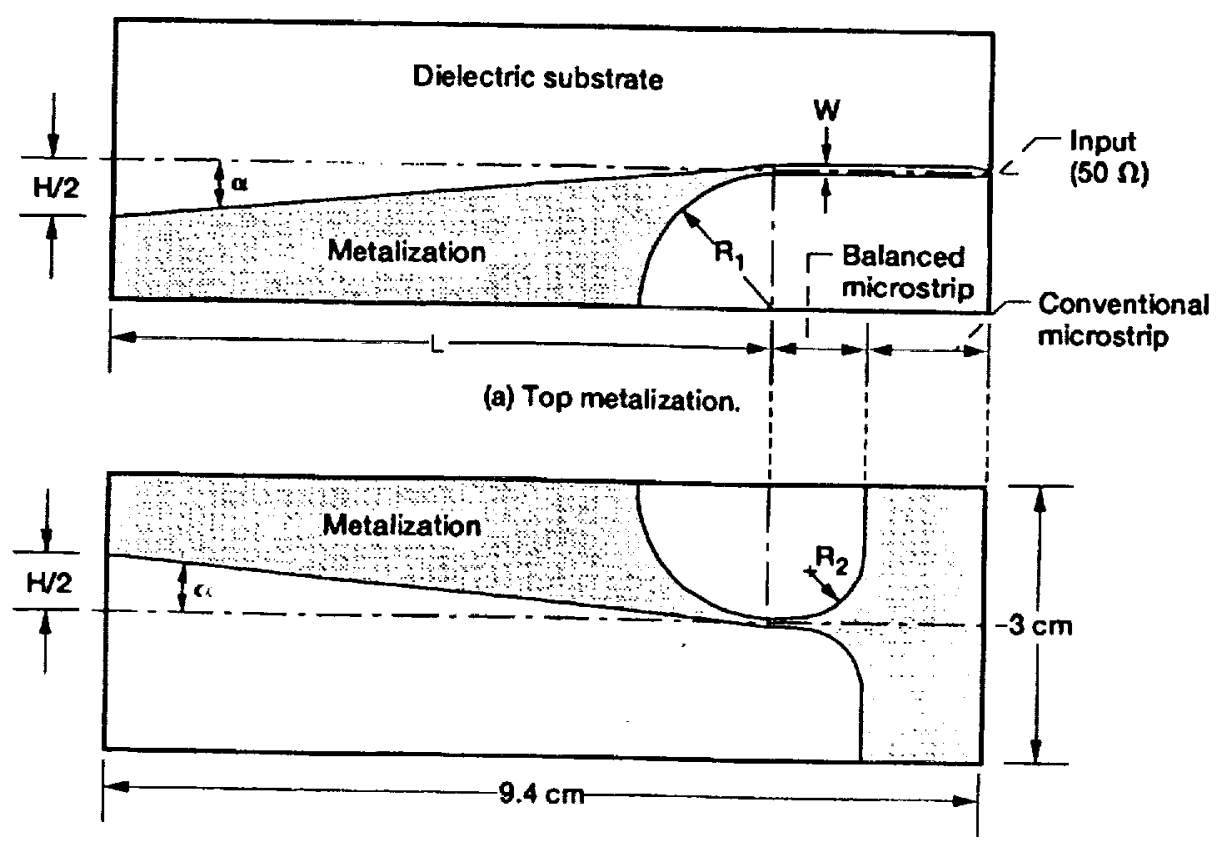

(b) Bottom metalization.

Figure 1.-Non-planar linearly tapered slot antenna and feed network. 

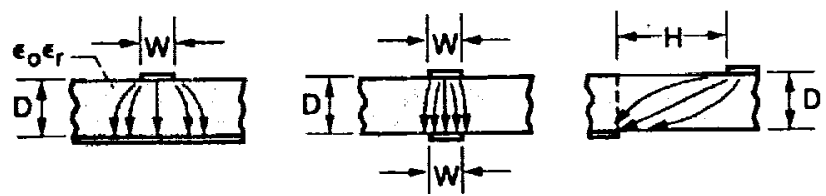

(a) Conventional microstrip.

(b) Balanced microstrip. (c) Antenna radiating edge.

Figure 2.-The electric field distribution at various cross sections.

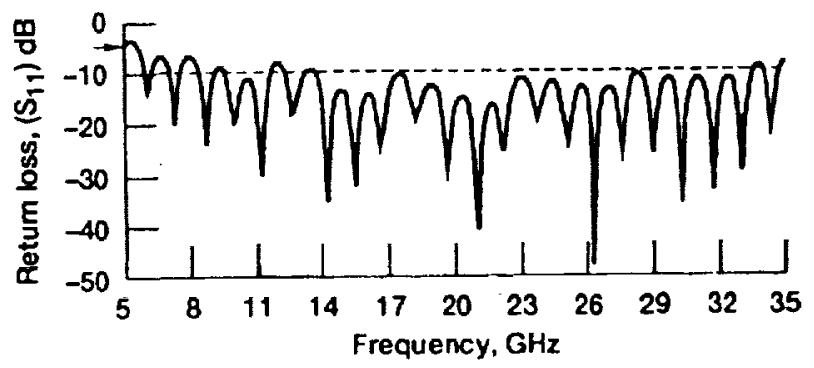

Figure 3.-Measured return loss $\left(S_{11}\right)$ at the coaxial input port.

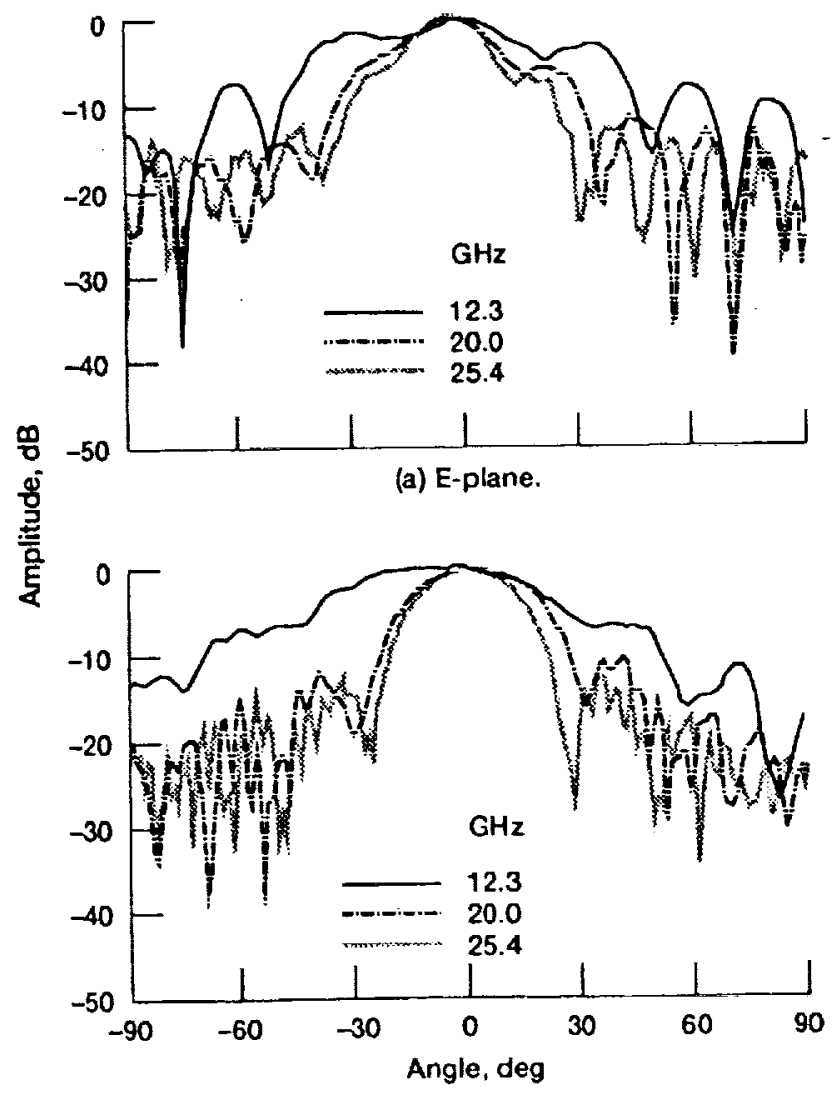

(b) H-plane.

Figure 4.-Measured radiation pattern of the non-planar LTSA. 